\title{
Studies in Long-Term Noise Statistics, Regional Climate Sensitivity and Predictability: Final Report (2003)
}

\author{
Kwang-Y. Kim, Principal Investigator

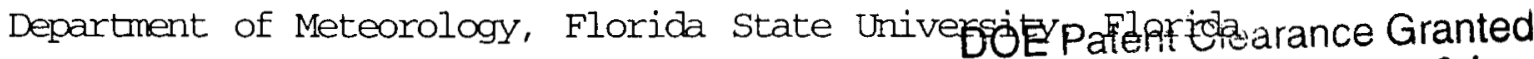

\section{SCIENTIFIC GOALS OF THE PROJECT:}

rpans cah

Mark P Dvorscak

(630) 25\%-2393

E-manl ingthduorscak@ch.doe.gov

Office on intititumal Property Law

The specific goals of the project were:

(1) to develop a family of simplified coupled climate modeqs Chy oriderating Office

results might be useful in benchmarking and comparing with the super models

to be developed under CHAMMP;

(2) to better understand the noise response characteristics of simple and complex coupled climate systems, which is an integral part of climate change studies;

(3) to address sampling problems arising from various estimation techniques based on finite length records and spatially sparse observations;

(4) to develop techniques of linear estimation problems such as detection, estimation and prediction that will ultimately be used to address the detectability and predictability at the regional scale; and

(5) to apply the developed tools to climate change studies.

\section{RESULTS TO DATE:}

(1) The PI developed many different versions of energy balance models (EBMs) to use them for the purpose of studying all the statistical issues of climate change problems. These simple coupled models were also used for the purpose of verifying climate statistics of coupled general circulation models (GCMs) and the uncertainty of climate change statement due to inaccurate model statistics.

(2) The capacity of cyclostationary EOFs (CSEOFs) in representing moving and -temporally evolving spatial patterns makes the CSEOF analysis technique suitable and attractive for climate change research. This useful tool allows the PI to cast the climate change problems into more revealing and interesting forms as discussed below. The computation of CSEOFs as they apply to climate change problems requires long data sets. At present, climate models are an only means of generating data sets long enough for reliable cyclostationary statistics of important physical variables. Model statistics are, of course, different from statistics of observational data. Therefore, it is important to understand whether model statistics will be reliable for long term climate change studies. During the report period, cyclostationary statistics of many model data sets have been examined in light of their reasonableness and comparability with observational data. The model data sets include the NCEP reanalysis data, ECMNF reanalysis data, 


\section{DISCLAMMER}

This report was prepared as an account of work sponsored by an agency of the United States Government. Neither the United States Government nor any agency thereof, nor any of their employees, makes any warranty, express or implied, or assumes any legal liability or responsibility for the accuracy, completeness, or usefulness of any information, apparatus, product, or process disclosed, or represents that its use would not infringe privately owned rights. Reference herein to any specific commercial product, process, or service by trade name, trademark, manufacturer, or otherwise does not necessarily constitute or imply its endorsement, recommendation, or favoring by the United States Government or any agency thereof. The views and opinions of authors expressed herein do not necessarily state or reflect those of the United States Government or any agency thereof. 


\section{DISCLAIMER}

Portions of this document may be illegible in electronic image products. Images are produced from the best available original document. 
ocean GCM data with observed wind and surface flux, assimilated sea level height, and longwave radiation data among others. It appears that the model statistics are quite reasonable for identifying physical processes that are sensitive to climate changes. These model data sets appear to be good proxies for the observational record.

The statistics of background noise or natural variability derived from coupled general circulation models (CGCMs) also seem to be reasonable. A detailed comparison of model statistics against those of observational data and other models is yet to be shown.

(3) The CSEOF analysis of several physical variables in global and regional domains reveals that some physical processes are good and reliable indicators of climatic changes whether natural or forced. For instance, the temporal evolution history of the Arctic Oscillation ( $A O)$ exhibits a strong trend, which can easily be detected from observational data. The signal-to-noise ratio (SNR) for this physical process is extremely high with a very tight confidence band. Another example includes the annual cycles of the $200 \mathrm{mb}$ temperature and the geopotential height fields. These physical processes also show remarkable trends, which imply the amplification of the annual cycles. This amolification is most likely related to greenhouse warming. The idea of identifying physical processes that are sensitive to climatic changes certainly deserves attention and has a high potential of being accurate indicators of regional and global climate changes. More importantly, changing physical processes, such as floods and droughts, are what affect the life on earth more strongly than global temperature change.

(4) Statements on the detectability and predictability of climate change signals are typically made based on one physical variable, say surface temperature. Uncertainty is inherent in such statements because neither the signal nor the natural variability of the adopted physical variable is completely known. One way to reduce the uncertainty associated with climate change problems is to use several physical variables in which an identical signal is investigated. If the identical signal is seen in many physical variables, -the confidence level will rise. The idea of detecting and predicting climate change signals in multivariate data is realizable as the compilation of large data sets accelerates.

one critical difficulty in a multivariate prediction and detection study is that a physically and dynamically consistent signal should be found in a multivariate data space. Namely, how would a signal in the surface temperature variable appear in the surface wind variable or $200 \mathrm{mb}$ geopotential height variable, etc. A signal in a multivariate space can be generated using a CGCM. Using COCMS is still computationally intensive and expensive. In light of using a sensitive physical process as an indicator of climatic change, a COCM simulation should still be analyzed to extract the consistent multivariate pattem of such a physical process. It appears that 
the extraction of a consistent signal in a multivariate space can be accomplished in an accurate manner by utilizing the CSEOF analysis.

(5) Once a consistent signal is found in a multivariate space, then predictability and detectability of such a signal should be explored. Thus, detection and prediction algorithms have been developed in a multivariate space. The natural variability of each physical variable should be known for such an exercise. An obvious advantage of multivariate detection and prediction methods is that the confidence of statistical inferences can greatly be enhanced by using more than one physical variable. Further, the chance of making a large pass-through error is greatly recuced because the realization of background noise differs from one physical variable to another.

(6) Finally, heat storage change in the deep ocean has been investigated in conjunction with the greenhouse warming. It appears that the heat storage change in the ocean is an important signature of greenhouse warming. For this study, a new energy balance model was developed with a simple upwelling-diffusion deep ocean with an interactive sea ice and surface albedo. A simulation with the observed trend of greenhouse gas concentration shows a realistic trend of heat storage comparable to the observational data. It seems that the heat storage change is a very robust signature of greenhouse warming. While the greenhouse warming signature is typically obscured by other naturally occurring climate changes such as volcanic eruptions in the surface temperature field, the greenhouse warming signature dominates the heat storage change in the decp ocean. Due to the long adjustment time scale of the deep ocean, such forcings as greenhouse forcing with long trends is much more strongly felt in the deep ocean than forcings with short time scales such as volcanic enuptions or sunspot fluctuations.

\section{PUBLICATIONS :}

The following papers were published under the sponsorship of the DOE during the project period.

Kim, K.-Y., and G. R. North, 1997: EOFs of harmonizable cyclostationary processes. J. Atmos. Sci., 54, 2416-2427.

Kim, K.-Y., 1997: Statistical interpolation using cyclostationary EOFs. J. Clim., 10, 2931-2942.

Kim, K.-Y., and G. R. North, 1998: EOF-based linear prediction algorithm: Theory. J. Clim., 11, 3046-3056.

Kim, K.-Y., and G. R. North, 1999: EOF-based linear prediction algorithm: Examples. J. Clim., 12, 2077-2092. 
Kim, K.-Y., and Q. Wi, 1999: A comparison study of EOF techniques: Analysis of nonstationary data with periodic statistics. J. Climate, 12, 185-199.

Crowley, T. J., and K.-Y. Kim, 1999: Modeling the temperature response to forced climate change over the last six centuries. Geophys. Res. Letter, 26, 1901-1094.

Kim, K.-Y., and Q. Wh, 2000: Optimal detection using cyclostationary EOFs. J. Climate, 13, 938-950.

Kim, K.-Y., 2000: Statistical prediction of cyclostationary processes. J. Climate, 13, 1098-1115.

Kim, K.-Y., and C. Chung, 2001: On the evolution of the seasonal cycle in the tropical Pacific. J. Climate, 14, 991-994.

Kim, K.-Y., 2002: Investigation of ENSO variability using cyclostationary EOFs of observational data. Meteor. Atmos. Phys., 81, 149-168.

Kim, K.-Y., and Y. Y. Kim, 2002: Mechanism of Kelvin and Rossby waves during ENSO events. Meteor. Atmos. Phys., 81, 169-189.

Lim, Y.-K., K.-Y. Kim, and H. S. Iee, 2002: Temporal and spatial evolution of the Asian summer monsoon in the seasonal cycle of synoptic fields. $J$. Clim., 15, 3630-3644.

Kim, K.-Y., J. J. O'Brien, and A. I. Barcilon, 2003: The principal physical modes of variability over the tropical Pacific. Earth Interactions, Vol 7, paper 3 .

Seo, K.-H., and K.-Y. Kim, 2003: Propagation and initiation mechanisms of the Madden-Julian Oscillation. J. Geophys. Res., 108, 4384.

Kim, K.-Y., and Y. Y. Kim, 2004: Investigation of tropical Pacific upper-ocean - variability using cyclostationary EOFs of observational data. Ocean. Dyn., in press. 